\title{
GENETIC DIVERGENCE IN LENTIL
}

\author{
S.D. TYAGI and M.H. KHAN \\ Department of Plant Breeding and Genetics, Kisan (P.G) College, Simbhaoli, Ghaziabad (U.P), India \\ Corresponding author: kmudasirhafiz@yahoo.com
}

(Received 18 March, 2010, accepted 28 May, 2010)

\begin{abstract}
Fifty genotypes of lentil (Lens culnaris Medik) were evaluated under eight environments for seed yield and its associated traits. All the genotypes were grouped into seven clusters. The composition of various clusters varied from 2 to 12. Clustering pattern revealed the distribution of the genotypes belonging to the same origin in more than one cluster indicating non-parallism between geographic and genetic diversity. Members of cluster II and VII were highly diverse from each other as these clusters showed maximum inter-cluster distance. The entries of cluster VII showed the highest mean values for number of primary branches ${ }^{-1}$, biological yield plant ${ }^{-1}$, seed yield plant $^{-1}$ and 100-seed weight. The promising genotypes for seed yield, 100 -seed weight, pods plant ${ }^{-1}$, seeds pod ${ }^{1}$ and early maturity were identified from cluster II and VII on the basis of mean values which could be utilized for hybridization programme for the development of high yielding genotypes.
\end{abstract}

Key Words: Clusters, genotypes, Lens culnaris

\section{RÉSUMÉ}

Cinquante génotypes de lentille (Lens culnaris Medik) étaient évalués dans huit environnements pour le rendement en grains et les caractères associés. Sept groupes de genotypes de compositions 2 à 12 étaient considérés. Le modèle de regroupement a révélé une distribution des genotypes appartenant à la même origine dans plus d'un groupe, indiquant qu'il n'y a pas de parallelism entre les diversités géographique et génétique. Les membres du groupe II et VII ont été très diverses les uns des autres avec une distance maximale entre les groupes. Les entrées du groupe VII ont montré des valeurs moyennes plus élevées du nombre de branches primaires par plante, le rendement biologique par plante, le rendement en grains par plante et le poids de 100 grains. Les génotypes prometteurs pour le rendement grains, le poids de 100 grains, le nombre de gousses par plant, le nombre de grains par gousse et la maturité précauce éaient identifiés à partir du groupe II et VII sur base des valeurs moyennes qui pourraient être utilisées dans le programme d’hybridation pour le développement de génotypes à haut rendement.

Mots Clés: Groupes, génotypes, Lens culnaris

\section{INTRODUCTION}

Among pulses, lentil (Lens culnaris Medik) with $2 n=14$ is one of the most important grain legume crop in India. It is one of the principal pulse crops cultivated in semi-arid regions of the world, particularly in the Indian sub-continent, and the dry areas of Middle East (Malik, 2005). It is estimated that India's population will touch nearly
1.35 billion by 2020 and will require 30 million tonnes of pulses as against the present production of 16.5 million tones (Anonymous, 2007). Clearly, a quantum jump is required in the total production of pulses to increase the per capita availability and to meet the challenges of increasing population. Conventional strategies for increasing the production of pulses include development and utilisation of improved plant 
varieties, production technologies and plant protection measures which are expected to reduce the existing gap in production and requirement of pulses.

The genetic reconstruction of plant type is required for developing high yielding varieties by improving yield component characters. The available genotypes will serve as the most valuable material reservoir for providing the desirable plant attribute for obtaining the high yielding crop varieties (Hawkis, 1981). The present study was conducted with an objective of selecting divergent parents for future use in improvement of lentil.

\section{MATERIALS AND METHODS}

Fifty genotypes of lentil obtained from National Bureau of Plant Genetic Resource, New Delhi, India were evaluated in Randomised Block Design with three replications during rabi season of two consecutive years 2006-07 and 2007-08 at Crop Research Farm, Kisan (PG) College, Simbhaoli $\left(28^{\circ} \mathrm{N}, 51^{0} \mathrm{E}\right)$, Ghaziabad (UP) India. The soil type of the experimental field was sandy loam with low available nitrogen (Subiah and Asija, 1956), medium available phosphorus (Olsen et al., 1954) and high potassium with neutral $\mathrm{pH}$ (Jackson, 1967). In each of the eight environments (2 sowing dates $\mathrm{x} 2$ fertiliser doses $\mathrm{x} 2$ years), each genotype was sown in field of three meter length spaced $20 \mathrm{~cm}$ apart with intra row spacing of 10 $\mathrm{cm}$. Eight environments were created by manipulating the dates of sowing and fertiliser doses with N: P: $S$ kg ha$^{-1}$ 20:40:20 and 10:20:10, dates of sowing as $1^{\text {st }}$ November and $1^{\text {st }}$ December. All recommended cultural practices and plant protection measures were followed to raise a healthy crop.

Data were recorded on 11 agronomical characters, namely days to $50 \%$ flowering, days to maturity, primary branches plant ${ }^{-1}$, secondary branches plant ${ }^{-1}$, number of pods plant ${ }^{-1}$, plant height, seeds pod ${ }^{-1}$, biological yield plant ${ }^{-1}$, seed yield plant ${ }^{-1}, 100$-seed weight, and harvest index from 10 randomly selected plants in each genotype at various phenophasis of the crop. Days to $50 \%$ flowering and days to maturity were recorded on plot basis.
The pooled data were subjected to multivariate analysis as suggested by Mahalanobis (1936) and genotypes were grouped into different clusters based on Tocher's method (Rao, 1952).

\section{RESULTS AND DISCUSSION}

The pooled analysis of variance revealed significant differences among genotypes for all the characters studied during both the years (Table 1) and thereby, indicating existence of a good amount of genetic variability. All the genotypes differed from each other with respect to these characters. Through multivariate analysis, the fifty genotypes were grouped into seven clusters based on $\mathrm{D}^{2}$ values (Table 2). The composition of different clusters varied from two to twelve genotypes. Cluster III comprised of twelve genotypes followed by cluster IV and V consisting of nine genotypes each. There were seven genotypes in clusters I and II, and four genotypes in cluster VI, while cluster VII had only two genotypes. The distribution of genotypes from different eco-geographical regions into these clusters was apparently random (Jeena and Singh, 2002). Genotypes of similar origin were grouped into different clusters and vice versa, thereby indicating non-relationship between geographical and genetic diversity. This tendency of genotypes to occur in clusters cutting across geographical boundaries demonstrates that geographical isolation is not the only factor causing genetic diversity (Sihag et al., 2004). This also suggests that the genotypes within cluster may have some degree of ancestral relationship. Similar findings were also reported by Sirohi et al. (2007), Solanki et al. (2000) and Kumar et al. (2004).

The genetic divergence is an outcome of several factors such as changing of breeding material, genetic drift, natural variation and artificial selection other than ecological and geographical diversification (Sirohi and Dar, 2009).

Therefore, selection of parents for hybridisation should be based on genetic diversity rather than geographic diversity to get more heterotic recombinants and desired 
transgressive segregants. However, caution should be taken in selecting divergent genotypes because such crosses may not yield proportionate heterotic response (Subhash Chandra et al., 2009). Therefore, a hybridisation programme may be initiated involving the genotypes belonging to diverse clusters with high means for almost all component traits. Furthermore, these divergent parents should have better combining ability to give results proportionate to heterotic response. Anunachalum (1981) also observed that the more diverse the parents are within their overall limits of fitness, the greater are the chances of heterotic expression of $\mathrm{F}_{1} \mathrm{~S}$ and a broad spectrum of variability in segregating generations.

The statistical distances among the different clusters are presented in Table 3. Maximum intracluster distance was observed in Cluster VI (2.042), followed by Cluster IV (2.004) indicating wide genetic variability within the genotypes of these two clusters. For inter-cluster distance, the maximum value was observed between Clusters II and VII (6.684) followed by cluster V and VII (6.290), which indicated maximum diversity between the genotypes of these clusters. Therefore, it is suggested that if the diverse genotypes from these groups along with the other desirable attributes are used in breeding programmes, it is expected to through better segregants for high seed yield and yield contributing traits due to non allelic interaction. The minimum inter-cluster distance between Clusters II and V (2.264) indicate that the genotypes of these clusters were genetically least diverse and almost of the same genetic architecture (Jeena and Singh, 2002) Such genotypes can also be used in breeding programmes for developing biparental crosses between the most diverse and closest groups to break the undesirable linkages between yield and its associated traits (Haddad, 2004).

The diversity was also supported by the appreciable amount of variation among the cluster means for different characters (Table 4). Cluster VII having two genotypes L-417 and L-4677 possesses either higher or lower value for most of the traits, justifying its inclusion as a separate cluster. Cluster VII exhibited the maximum mean value for primary branches plant ${ }^{-1}$, biological yield 
TABLE 2. Distribution of 50 genotypes of lentil in different clusters

\begin{tabular}{|c|c|c|}
\hline Cluster & Number of genotypes & Genotypes included \\
\hline I & 7 & L-415, L-393, L-32225, L-412, L-4597, L-416, L-4661 \\
\hline II & 7 & L-830, K-75, DPL-59, PL-81-18, PL-81-1, MC-6, Pusa-4 \\
\hline III & 12 & L-308, L-309, L-4676, L-386, L-381, L-4594, L-4148, L-4598, L-4147, L-4596, L-414, L-310 \\
\hline IV & 9 & L-307, L-4595, L-4674, L-306, L-4618, L-4671, L-395, L-4672, L-4620 \\
\hline V & 9 & PL-81-41, L-1304, PL-81-71, PL-81-59, PL-81-10, PL-81-53, PL-81-61, PL-234, LC-163-4-1 \\
\hline $\mathrm{VI}$ & 4 & JLS-1, LC-362, PKVL-1, P-22201 \\
\hline VII & 2 & L-417, L-4677 \\
\hline
\end{tabular}

TABLE 3. Average inter- and intra (bold values) distances involving 50 genotypes of lentil

\begin{tabular}{llllllll}
\hline Clusters & I & II & III & IV & V & VI & VII \\
\hline I & 1.630 & & & & & & \\
II & 4.840 & 1.991 & & & & & \\
III & 2.816 & 5.603 & 1.746 & & & & \\
IV & 2.686 & 4.368 & 3.226 & 2.004 & & & \\
V & 4.181 & 2.264 & 5.352 & 3.354 & 1.916 & & \\
VI & 4.501 & 3.534 & 4.988 & 4.589 & 3.034 & 2.042 & 0.030 \\
VII & 2.841 & 6.684 & 3.797 & 4.967 & 6.290 & 6.156 & \\
\hline
\end{tabular}

plant $^{-1}$, seed yield plant ${ }^{-1}$ and 100 -seed weight. Cluster VI had early maturing genotypes with secondary branches plant ${ }^{-1}$, pods plant ${ }^{-1}$ and more number of seeds pod $^{-1}$; whereas cluster II had genotypes with maximum harvest index and early maturity. These results showed that different clusters were superior for different characters.

The parents for hybridisation could be selected on the basis of their large inter- cluster distance for isolating useful recombinants in the segregating generations. The better performing genotypes from Clusters II and VII were identified for all the traits. The genotypes viz., DPL-59, L830, K-75, PL-81-1 and PL-81-18 were identified as donors for seed pod $^{-1}$ and early maturity. The hybridisation programme involving genotypes L417, L-4677 from Cluster VII and P-81-18, DPL-59, L830, K-75 and P-81-18 from Cluster II could be under-taken to isolate high yielding segregants, since these genotypes have high yielding potential, more number of primary branches, more biological yield, high harvest index, high 100-seed weight and early maturity with more genetic distances (Table 5). Therefore, progenies derived from such diverse crosses are expected to show wide spectrum of genetic variability and a greater scope for isolating transgressive segregants in the advanced generations. Hence, these genotypes might be used in a multiple crossing programme to recover transgressive segregants.

\section{REFERENCES}

Anonymous. 2007. Hand Book of Agriculture. ICAR Publication, New Delhi, India.

Arunachalam, V. 1981. Genetic divergence in plant breeding. Indian Journal of Genetics 41:226.

Haddad, N. I., Boggo, T. P. and Muchibauer, F. J. 2004. Genetic variation of six agronomic characters in three lentil (Lens culinaris Medik.) crosses. Euphytica 31:113-120.

Hawkes, J.G. 1981. Germplasm collection preservation and use In: KJ Frey (Ed.), pp. 57-84. Plant Breeding. Iowa State University Press, Iowa, USA.

Jackson, M.L. 1967. Soil Chemical Analysis Prentice Hall Inc., England, Cliffs, N. J. 
TABLE 5. Potent genetic donors in lentil identified from cluster II and VII for different characters

\begin{tabular}{ll}
\hline Characters & Promising genotypes \\
\hline High seed yield & $>8.60:$ L-417, L-4677 \\
100-seed weight & $>5.13:$ L-417, L-4677 \\
Pods plant-1 & $>82.33:$ L-417, L-4677, PL-81-18 \\
Seeds pod-1 & $>1.67:$ DPL-59, L-830, K-75, PL-81-1 \\
Early maturity & $<110:$ PL-81-18, PL-81-1, K-75 \\
\hline
\end{tabular}

Jeena, A.S. and Singh, I. S. 2002. Genetic divergence analysis in wild lentils. Legume Research 25(3):175-179.

Kumar, R., Sharma, S.K., Malik, B.P.S., Sharma, A. and Sharma, R. 2004. Genetic diversity in lentil (Lens culnaris Medik). Legume Research 27(2):111-114.

Mahalanobis, P.C. 1936. On the generalized distance in statistics. Proceedings of National Institute of Science India 2:49-55.

Malik, R. 2005. Genetic divergence analysis in lentil (Lens culnaris Medik). M.Sc. Thesis, Department of Agricultural Botany, Ch. Charan Singh University, Meerut (U.P.), India. 1pp.

Olsen, S.R., Cole, C.V., Watanabe, F. S. and Dean L. A. 1954. Estimation of available phosphorus in soil by extraction with sodium bicarbonate. United States Department of Agricultural Circular 939. pp. 19.

Rao, C.R. 1952. Advanced Statistical Methods in Biometric Research. John Wiley and Sons Inc. New York. pp. 390.

Sihag, R., Hooda J.S., Vashishtha, R.D. and Malik, B.P.S. 2004. Genetic divergence in soybean [Glycine max (L.) Merrill]. Annals Biol. 20(1): 17-21.

Sirohi, S.P.S., Yadav, R. and Meenakshi, S. 2007. Assaying genetic divergence for morphophysiological traits in lentil (Lens culnaris Medik). Plant Archies 7(1): 331-333.

Sirohi, S. P. S. and Dar, A. N. 2009. Genetic divergence in soybean (Glycine max L. Merrill). SKUAST Journal of Research 11(2): 200-203.

Solanki, I.S. 2007. Divergence analysis in lentil (Lens culnaris Medik). National Journal of Plant Improvement 9(2):123-125. 
Subbiah, B. V. and Asifa, C.L. 1956. A rapid procedure for estimation of available nitrogen in soil. Current Science 251:238-268.

Subhashchandra, B., Lohithaswa, H. C., Desai, S. A., Hanchinal, R.R., Kalappanavar, I.K., Math, K.K. and Salimath, P.M. 2009. Assessment of genetic variability and relationship between genetic diversity and transgressive segregation in tetraploid wheat. Karnataka Journal of Agricultural Science 22 (1):3638. 